\title{
Recent advances in the management of difficult bile-duct stones: a focus on single-operator cholangioscopy-guided lithotripsy
}

\author{
Chi Hyuk Oh and Seok Ho Dong
}

Division of Gastroenterology and Hepatology, Department of Internal Medicine, Kyung Hee University Hospital, Seoul, Korea

Received: August 14, 2020 Accepted: September 14, 2020

\section{Correspondence to}

Seok Ho Dong, M.D.

Division of Gastroenterology and Hepatology, Department of Internal Medicine, Kyung Hee University Hospital, 23 Kyungheedae-ro, Dongdaemun-gu, Seoul 02447, Korea

Tel: +82-2-958-8149

Fax: +82-2-958-8150

E-mail: gidrdong@hanmail.net https://orcid.org/0000-00023969-8229
The most effective and the standard treatment for bile duct stones (BDSs) is endoscopic retrograde cholangiopancreatography (ERCP). However, in $10 \%$ to $15 \%$ of patients with BDSs, the stones cannot be removed by conventional ERCP, which involves endoscopic sphincterotomy followed by balloon or basket extraction. Additional techniques or devices are often necessary to remove these difficult bileduct stones, including endoscopic papillary large balloon dilatation to make a larger papillary opening and/or mechanical lithotripsy to fragment the stones. Advances in cholangioscopy have made possible electrohydraulic or laser lithotripsy under direct cholangioscopic visualization during ERCP. Cholangioscopy-guided lithotripsy could be another good option in the armamentarium of techniques for removing difficult BDSs. Here we review endoscopic techniques based on single-operator cholangioscopy for the management of difficult BDSs.

Keywords: Cholangiopancreatography, endoscopic retrograde; Choledocholithiasis; Lithotripsy; Cholangioscopy

\section{INTRODUCTION}

Bile duct stones (BDSs) are one of the most common biliary tract diseases, with a prevalence of $10 \%$ to $20 \%$ in patients with symptomatic gallbladder stones $[1,2]$. Patients with BDSs are at high risk of serious, potentially fatal complications, such as acute cholangitis, liver abscess, or acute gallstone pancreatitis. Endoscopic retrograde cholangiopancreatography (ERCP) is a standard procedure for the treatment of patients with BDSs. Approximately 90\% of BDSs can be effectively removed with endoscopic sphincterotomy (EST) followed by stone extraction. However, the remaining $10 \%$ to $15 \%$, which are considered difficult BDSs, often require additional techniques or devices for their removal [3]. These include cases in which access to the bile duct is challenging (e.g., periampullary diverticulum, altered anatomy after gastric bypass), and/or the size, shape, or location of the stones within the bile duct is difficult to determine for mechanical lithotripsy (ML) and extraction. ML and endoscopic papillary large balloon dilatation (EPLBD) are now the standard techniques for the removal of large BDSs. Cholangioscopy has been developed over the last decade and enables the management of BDSs by providing direct access to the bile duct. The second generation of digital single-operator cholangioscopy (SOC) is available and facilitates the management of difficult BDSs. This review highlights various aspects of difficult BDSs and SOC with a focus on recent strategies for SOC-guided lithotripsy. 
Table 1. Difficult bile-duct stones

\begin{tabular}{|c|c|c|}
\hline Category & Conditions & Reasons \\
\hline Characteristics of stone & $\begin{array}{l}\text { Large stone }(>15 \mathrm{~mm}) \\
\text { Multiple stones }(>3 \text { stones, size }>10 \mathrm{~mm}) \\
\text { Hard stone } \\
\text { Strange-shaped stone }\end{array}$ & $\begin{array}{l}\text { Need for lithotripsy and difficulty in } \\
\text { capturing the stone with a basket }\end{array}$ \\
\hline Location of stone & $\begin{array}{l}\text { Intrahepatic duct stone } \\
\text { Stone above a stricture } \\
\text { Impacted stone in the bile duct/cystic duct } \\
\text { Mirizzi syndrome }\end{array}$ & Difficulty in access \\
\hline Anatomical situation & $\begin{array}{l}\text { Altered anatomy } \\
\text { Billroth II/Roux-en-Y gastric bypass anatomy } \\
\text { Periampullary diverticulum }\end{array}$ & $\begin{array}{l}\text { Difficulty in biliary access and limitation } \\
\text { of the endoscope/accessory }\end{array}$ \\
\hline Patient factors & $\begin{array}{l}\text { Old age/poor general condition } \\
\text { Unstable vital signs } \\
\text { Bleeding tendency } \\
\text { Paradoxical response }\end{array}$ & Risk of adverse events \\
\hline
\end{tabular}

\section{DIFFICULT BILE-DUCT STONES}

No clear consensus exists about the definition of difficult BDSs. Factors that contribute to the difficulty in removing BDSs can be divided into four major categories: (1) stone characteristics, such as stone size $>15$ $\mathrm{mm}$, multiple stones, hard stones, and strange shape of stones (e.g., barrel shape); (2) stone location, such as in the intrahepatic duct (IHD), above a stricture, or impacted in the bile duct/cystic duct; (3) anatomical alterations that make access to the papilla challenging, such as the presence of a periampullary diverticulum, Roux-en-Y gastric bypass anatomy, and Billroth II anatomy; and (4) patient factors, such as bleeding tendency due to the use of an antithrombotic agent, age $>65$ years, and unstable vital signs (Table 1).

\section{ENDOSCOPIC MANAGEMENT OF DIFFICULT BILE-DUCT STONES}

The removal of difficult BDSs cannot be achieved with conventional ERCP, which involves EST followed by balloon or basket extraction. Thus, additional techniques including EPLBD, ML, and cholangioscopy-guided lithotripsy may be required.

\section{Endoscopic papillary large balloon dilation}

According to the 2019 guidelines of the European Society of Gastrointestinal Endoscopy (ESGE) [4], EST combined with EPLBD is recommended as the initial step in removing difficult BDSs. EPLBD was first described by Ersoz et al. [5] in 2003. It is performed with a dilation balloon of diameter $>12 \mathrm{~mm}$. EPLBD can be used to dilate the biliary orifice using a large-diameter (typically 12 to $20 \mathrm{~mm}$ ) balloon. Several studies on difficult BDSs have demonstrated the efficacy and safety of EPLBD. Additionally, EST + EPLBD reduces the need for ML by $30 \%$ to $50 \%$ compared with EST alone $[6,7]$. As a result, EPLBD after EST has become the standard technique for the management of difficult BDSs.

The adverse events (AEs) of EPLBD are mainly pancreatitis, bleeding, and perforation (the most serious $\mathrm{AE})$. Distal common bile duct (CBD) stricture is an independent risk factor for perforation and is considered a relative contraindication to EPLBD. However, EST + EPLBD reduces the rate of AEs such as perforation. In a systematic review, the rate of AEs was significantly lower for EST + EPLBD than for EST alone (8.3\% vs. 12.7\%; odds ratio [OR], 1.6o; $p<0.001)$ [8].

\section{Mechanical lithotripsy}

ML is an effective technique for crushing large or hard BDSs. The ESGE guidelines recommend ML when EST and EPLBD have failed or are inappropriate [4]. The gen- 
Table 2. Three types of cholangioscopy system

\begin{tabular}{lccc}
\hline & $\begin{array}{c}\text { "Mother-baby" } \\
\text { dual-operator } \\
\text { cholangioscopy }\end{array}$ & $\begin{array}{c}\text { Single-operator } \\
\text { cholangioscopy } \\
\text { (SpyGlass DS system) }\end{array}$ & $\begin{array}{c}\text { Direct peroral } \\
\text { cholangioscopy } \\
\text { (ultra-slim endoscope) }\end{array}$ \\
\hline Endoscopist & 2 & 1 & 1 \\
Additional endoscope system & Yes & Yes & No \\
Scope diameter, mm & $3.3-3.5$ & 3.6 & $5-6$ \\
Accessory channel, $\mathrm{mm}$ & 1.2 & 1.2 & 2 \\
Irrigation channel & No & Yes & No \\
Cost & High & High & Low \\
Image quality & High & Intermediate & High \\
\hline
\end{tabular}

erally used stone extraction basket cannot crush a hard stone because the basket wires are thin and weak. The ML basket captures the stone in a strong basket and then breaks it against a metal sheath. With the introduction and increased utilization of EPLBD, the use of ML has decreased. However, ML may be required if the stone is too large to remove after EPLBD, a stricture exists below the stone, or a traditional basket is impacted with a stone in the bile duct [9].

Although ML may require multiple sessions, it has been reported to be an effective and safe technique. The success rates range from $76 \%$ to $91 \%$, and the overall rates of AEs range from $3 \%$ to $34 \%$ [10-14]. In a retrospective study by Lee et al. [12], stone impaction, stone size $>30 \mathrm{~mm}$, and stone to CBD diameter ratio >1 were significant predictors of ML failure. ML is associated with high rates of AEs, including cholangitis, hemorrhage, pancreatitis, and perforation [9]. The most common and feared AEs of ML are an impacted basket, a broken basket, traction wire fracture, or a broken handle [15].

Although the technical success rate of ML is approximately $90 \%$, the procedure can be technically challenging depending on the size and location of the BDSs. An impacted stone is a risk factor for failure of $\mathrm{ML}$, and a confluence stone is also technically challenging to manage. However, these difficulties and limitations have been overcome by the development of cholangioscopy-guided electrohydraulic lithotripsy (EHL) and cholangioscopy-guided laser lithotripsy (LL) [16-19].

\section{CHOLANGIOSCOPY-GUIDED LITHOTRIPSY}

\section{Cholangioscopy system}

Cholangioscopy is useful in the diagnosis and treatment of bile duct abnormalities, and was developed to overcome the limitations of ERCP. Three types of peroral cholangioscopy (POC) are currently available (Table 2) $[20,21]$ :

1. "Mother-baby" endoscope system: This system requires one operator to handle the duodenoscope and another to handle the cholangioscope.

2. SOC using the SpyGlass DS system: In this method, a digital and single-use cholangioscope is attached to the duodenoscope, allowing a single operator to manage the control of both scopes.

3. Direct POC using an ultra-slim endoscope: Direct access to the bile duct is a good option for the management of large BDSs because it offers direct visualization of the stone during therapy. However, because dual-operator cholangioscopy and direct cholangioscopy systems with an ultra-slim endoscope are inconvenient to use, expensive, and relatively thick, their application to the management of difficult BDSs has several limitations.

The mother-baby technique using classic cholangioscopes is limited by their fragility, cost, complex and difficult installation, two-way tip deflection only, and the need for two experienced endoscopists. Therefore, they are rarely used at present.

\section{Single-operator cholangioscopy}

SOC, through the introduction of the SpyGlass DS Di- 
rect Visualization System (Boston Scientific, Marlborough, MA, USA), has led to a rapid increase in the use of cholangioscopy (cholangioscopy using the SpyGlass system is usually referred to as SOC). SpyGlass is a digital and single-use cholangioscope that overcomes several limitations of other types of cholangioscopes. Because this digital cholangioscope has a diameter of approximately $3.5 \mathrm{~mm}$, it can be used to access the bile duct directly through the working channel of a duodenoscope. Because it is a 'plug-and-play' device, it is easy and quick to set up. This cholangioscope has both a $1.2 \mathrm{~mm}$ accessory channel and a $1.2 \mathrm{~mm}$ suction channel. Through the thin accessory channel, instruments, such as an EHL or LL probe, can be inserted and used for lithotripsy (Fig. 1).

The next generation of the SpyGlass DS System (SpyGlass DS 2.0) has recently been released. It has fourfold higher image resolution and optimized light emitting diode (LED) illumination, promising improved diagnostic and therapeutic capabilities.
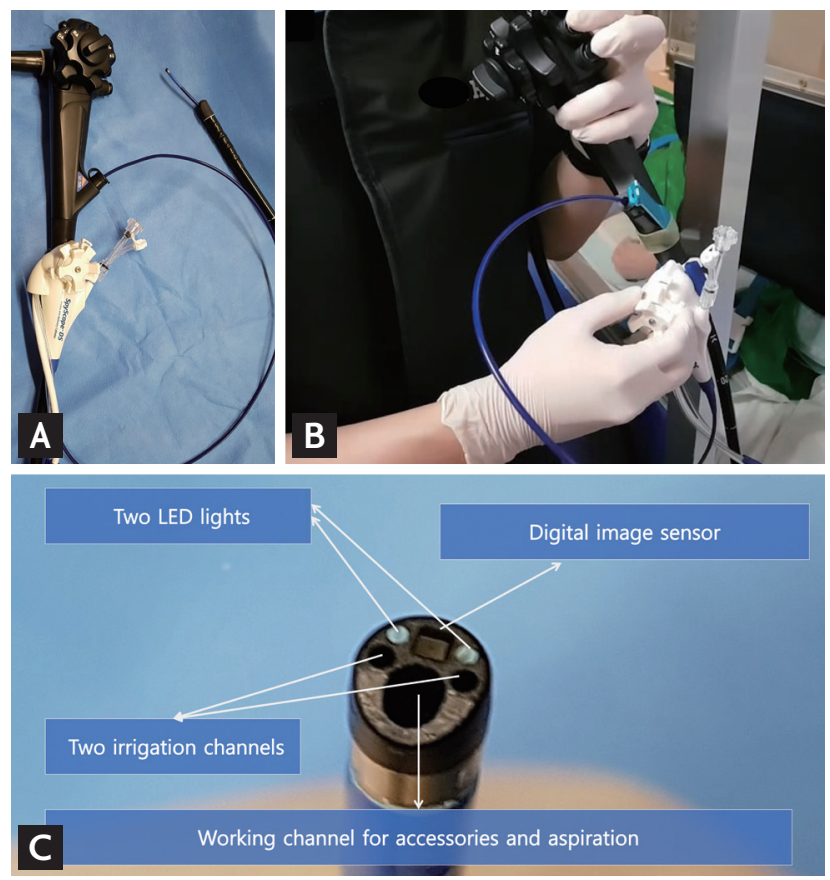

Figure 1. Single-operator cholangioscopy (SOC) using the SpyGlass DS system (Boston Scientific). (A) The SpyScope is inserted into the duodenoscope through its working channel. (B) A single endoscopic retrograde cholangiopancreatography endoscopist operates both the duodenoscope and the SOC (hence 'single-operator' cholangioscopy). (C) The SpyScope, the digital, single-use scope of the SpyGlass DS System. Its diameter is $3.6 \mathrm{~mm}$. The diameter of the working channel is $1.2 \mathrm{~mm}$. LED, light emitting diode.

\section{Cholangioscopy-guided lithotripsy}

\section{Electrohydraulic lithotripsy}

In this method, an EHL probe made of a coaxial bipolar device is passed into the working channel of the endoscope. EHL is based on the principle that, when a charge is applied, sparks generated underwater produce high-frequency hydraulic pressure waves. The energy is absorbed by the stones and results in their fragmentation. The probe is used with the probe tip 1 to $2 \mathrm{~mm}$ from the stone. Continuous saline irrigation is required to provide a medium for shock-wave energy transmission. Additionally, saline irrigation enables the maintenance of optimal vision during lithotripsy. Because direct bile-duct damage caused by shock waves can lead to bleeding or perforation, it is important to perform lithotripsy with direct visualization using cholangioscopy.

\section{Laser lithotripsy}

In LL, a laser light at a particular wavelength is focused on the surface of the stone to induce wave-mediated fragmentation. The first successful use of a pulsed laser for shock-wave lithotripsy of BDSs was reported in 1986 [22]. The technology has evolved since then, and other laser types, such as an neodymium:yttrium aluminum garnet (Nd:YAG) laser with an automatic stone recognition system and the frequency-doubled double-pulse Nd:YAG laser system, have been introduced $[23,24]$. The tip of the laser fiber has a green (or white) aiming beam, which is used to target the stone under direct vision. With the probe tip 1 to $2 \mathrm{~mm}$ from the stone and under continuous saline irrigation, laser bursts are delivered through the aqueous medium until stone fragmentation is deemed complete.

\section{SOC-GUIDED LITHOTRIPSY}

\section{Indications for SOC-guided lithotripsy}

No clear guidelines exist for SOC-guided lithotripsy, including those for indications, selection of cholangioscope type, and choice between EHL and LL [20]. The ESGE guidelines suggest that the type of cholangioscopy and lithotripsy should depend on local availability and experience [4]. Instead, the inclusion criteria of several studies on SOC-guided lithotripsy have suggested sit- 
uations in which SOC-guided lithotripsy should be actively considered: stone size $>20 \mathrm{~mm}$, multiple stones $>10 \mathrm{~mm}$, stones proximal to a stricture, stones in the IHD, stones in difficult-to-access locations (cystic duct or IHD), impacted stones in the bile or cystic duct, lumen-occupying stone casts, and at least two failed attempts of stone clearance using conventional means.

\section{Procedure, technique, and protocol}

EST is performed before SOC. The choice of the SOC-guided lithotripsy method (EHL or LL) depends on system availability and the preferences of the endoscopist. When performing SOC, the SpyScope, which is a digital and single-use cholangioscope in the SpyGlass DS System, is inserted into the bile duct in a freehand or guidewire-guided method. The SpyScope is advanced into the CBD or cystic stump toward the stone of interest, with endoscopic vision and intermittent fluoroscopy. When deemed necessary, the SpyScope is advanced over the guidewire to the target site. After direct visualization of the stone, the guidewire is replaced by the EHL probe (Fig. 2). When using the holmium laser tech-
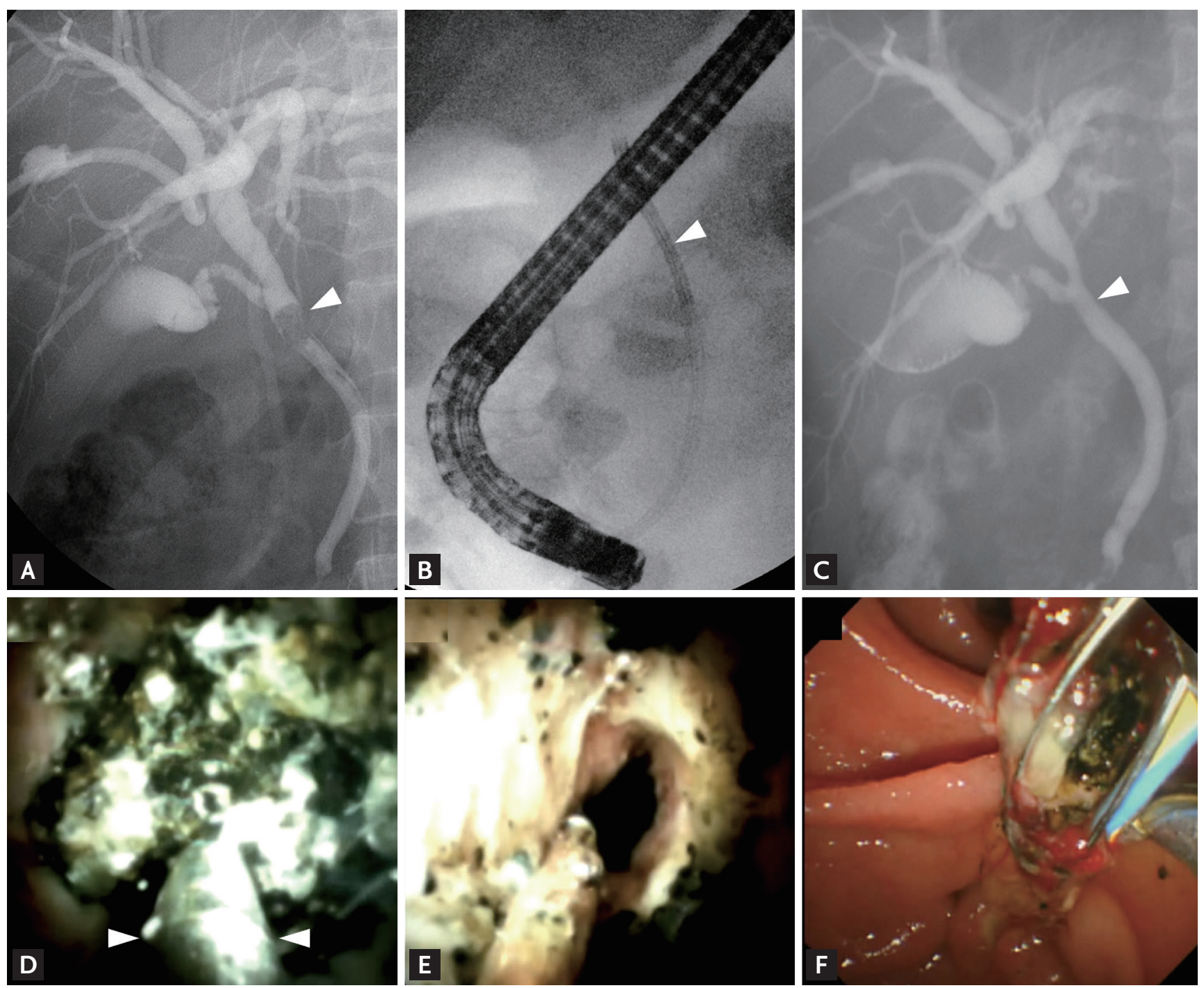

Figure 2. Single-operator cholangioscopy (SOC)-guided electrohydraulic lithotripsy (EHL). (A) Endoscopic retrograde cholangiopancreatography (ERCP) image showing an impacted bile duct stone (arrowhead). (B) Fluoroscopy image showing SOC (arrowhead) inserted into the bile duct. (C) Final ERCP image showing no residual filling defect after lithotripsy (arrowhead). (D) SOC image showing an impacted stone. EHL (arrowheads, EHL probe) is performed under endoscopic view. (E) SOC image showing the cleared bile duct after lithotripsy. (F) Fragmented bile duct stones are extracted using a multi-wire basket after lithotripsy. 


\section{KJIM}

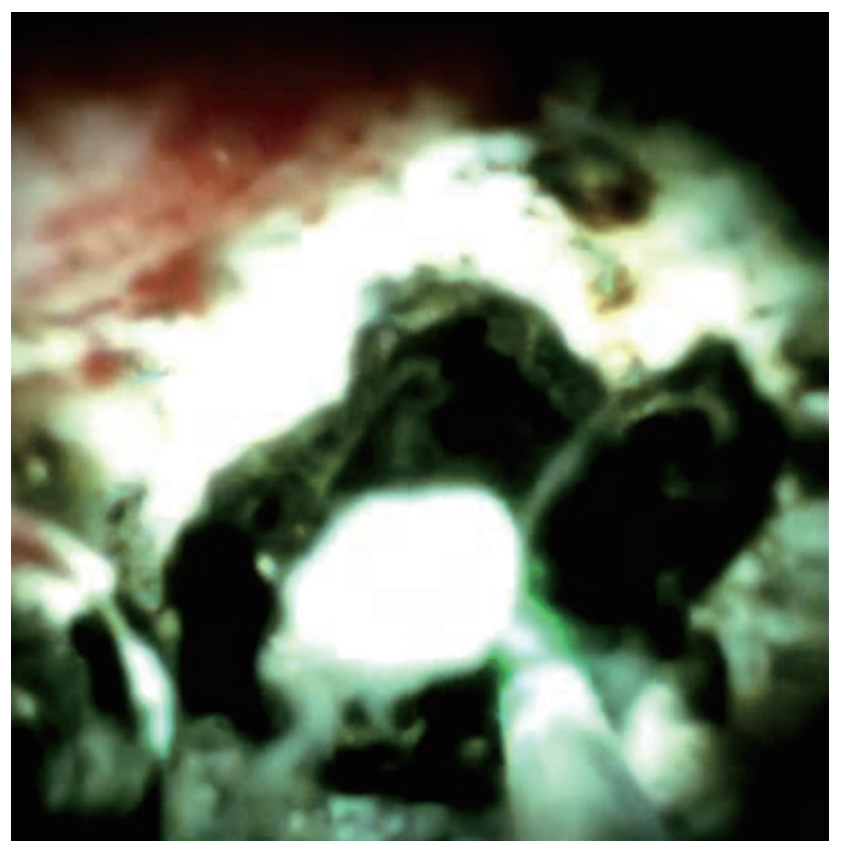

Figure 3. Single-operator cholangioscopy-guided laser lithotripsy. Green aiming beam from the laser fiber (probe) targeting and fragmenting the impacted stone.

nology, the LL fiber is inserted into the $1.2 \mathrm{~mm}$ working channel of the SpyScope (Fig. 3). The energy of the laser fiber or EHL probe is delivered until stone fragmentation is deemed complete. The fragmented stones are removed using conventional extraction devices, which may include ML, at the discretion of the endoscopist. If complete ductal clearance is not achieved in a single session, one or more plastic biliary stents or a nasobiliary drain catheter is inserted until the next session.

Inserting an EHL or LL probe into the accessory channel of the SpyScope can be impossible because of strong resistance. This is because when the SpyScope is located inside the bile duct, an acute angulation is made by the twisted distal end of the duodenoscope and its elevator. After straightening the SpyScope by withdrawing to the duodenum, the probe can be more easily inserted. Thereafter, the SpyScope is re-inserted into the bile duct.

During SOC-guided EHL or LL, continuous saline irrigation is required to provide a medium for electric shock waves or laser bursts. However, in some situations, such as after full EST and EPLBD, it is impossible to fill the bile duct with saline. Various strategies can be attempted to overcome this situation-changing the patient's position may be a good and easy solution.
Increasing the irrigation pressure using a water pump can also be a good technical alternative. In addition, SOC-guided lithotripsy can be performed after occluding the bile duct with a balloon catheter. However, this procedure is complex and time consuming because it requires re-inserting the duodenoscope.

\section{Efficacy of SOC-guided lithotripsy}

Several studies have demonstrated the successful management of difficult biliary stones using cholangioscopy-guided LL and EHL, with success rates ranging from $67 \%$ to $100 \%$ [19,24-31].

In a meta-analysis of 49 studies, the overall stone clearance rate was $88 \%$ (95\% confidence interval [CI], $85 \%$ to $91 \%$ ) [28]. However, this study investigated all types of cholangioscopy-guided lithotripsy, including SOC-guided lithotripsy. Recent studies focusing on SOC-guided lithotripsy have reported better efficacy (Table 3) [19,26,27,29-34].

In a recent systematic review and meta-analysis of 24 studies, Jin et al. [35] analyzed the efficacy and safety of SOC-guided lithotripsy in treating difficult BDSs. The rate of complete stone clearance was 94\% (95\% CI, 90.2\% to $97.5 \%)$. The rate of single-session stone clearance was $71.1 \%$ (95\% CI, $62.1 \%$ to $79.5 \%$ ) in the pooled 2786 patients. The number of sessions needed for complete stone clearance was 1.26 (95\% CI, $1.17 \%$ to $1.34 \%$ ).

In a recent retrospective study, Bokemeyer et al. [29] reported that SOC-guided lithotripsy was successful in $95 \%$ of patients, with $15 \%$ needing at least two treatment sessions. They concluded that SOC-guided lithotripsy is an excellent rescue approach even in patients with difficult stones in whom previous conventional ERCP had failed. Additionally, they reported that SOC-guided lithotripsy reduced radiation exposure compared with the conventional ERCP method.

In a retrospective study of 407 patients who underwent POC for difficult biliary stones at 22 tertiary centers in the United States, United Kingdom, and Korea, technical success, defined as complete stone clearance, was achieved in $97.3 \%$ with a median number of lithotripsy sessions of 1 (range, 1 to 4 sessions) [27]. In a multivariate analysis, difficult anatomy and cannulation were associated with technical failure (adjusted OR, 5.18; 95\% CI, 1.26 to $21.2 ; p=0.02$ ) and the duration of the procedure was a predictor of the need for more than one session 
Table 3. Efficacy of single-operator cholangioscopy-guided lithotripsy

\begin{tabular}{|c|c|c|c|c|c|c|c|}
\hline Study & Study design & Lithotripsy & $\begin{array}{c}\text { No. of } \\
\text { patients }\end{array}$ & $\begin{array}{c}\text { Clearance, } \\
\%\end{array}$ & $\begin{array}{c}\text { Clearance } \\
\text { after } 1 \\
\text { session, \% }\end{array}$ & $\begin{array}{c}\text { Mean no. } \\
\text { of proce- } \\
\text { dure }\end{array}$ & $\begin{array}{c}\text { Mean size } \\
\text { of stone, } \\
\mathrm{mm}\end{array}$ \\
\hline Kurihara et al. (2016) [30] & $\begin{array}{l}\text { Multicenter } \\
\text { Prospective }\end{array}$ & $\mathrm{EHL}+\mathrm{LL}$ & 31 & 74.2 & & 1.9 & 20.6 \\
\hline Bhandari et al. (2016) [19] & Single center & LL & 34 & 100 & 94.1 & 1.1 & \\
\hline $\begin{array}{l}\text { Navaneethan et al. (2016) } \\
{[31]}\end{array}$ & $\begin{array}{l}\text { Multicenter } \\
\text { Retrospective }\end{array}$ & LL & 31 & $97 \cdot 2$ & 86.1 & 1.1 & $14 \cdot 9$ \\
\hline Wong et al. (2017) [26] & Single center & $\mathrm{EHL}+\mathrm{LL}$ & 17 & 100 & 94.1 & & 17 \\
\hline Brewer et al. (2018) [27] & $\begin{array}{l}\text { Multicenter } \\
\text { Retrospective }\end{array}$ & $\mathrm{EHL}+\mathrm{LL}$ & 407 & $97 \cdot 3$ & $77 \cdot 4$ & 1 & \\
\hline Buxbaum at al. (2018) [37] & $\begin{array}{l}\text { Single center } \\
\text { Prospective }\end{array}$ & LL & 42 & 93 & & 1.9 & 18 \\
\hline Turowski et al. (2018) [32] & $\begin{array}{l}\text { Multicenter } \\
\text { Retrospective }\end{array}$ & $\mathrm{EHL}+\mathrm{LL}$ & 107 & 91.1 & & 3 & \\
\hline $\begin{array}{l}\text { Angsuwatcharakon et al. } \\
(2019)[33]\end{array}$ & $\begin{array}{l}\text { Multicenter } \\
\text { Prospective }\end{array}$ & LL & 32 & 100 & 100 & 1 & 19.5 \\
\hline Bokemeyer et al. (2020) [29] & $\begin{array}{l}\text { Multicenter } \\
\text { Retrospective }\end{array}$ & $\mathrm{EHL}+\mathrm{LL}$ & 60 & 95 & 67 & & 20 \\
\hline
\end{tabular}

EHL, electrohydraulic lithotripsy; LL, laser lithotripsy.

to achieve complete stone clearance (adjusted OR, 1.02; 95\% CI, 1.01 to 1.03; $p<0.001$ ). The authors concluded that SOCguided lithotripsy is effective and safe in > 95\% of patients with difficult BDSs.

In a prospective study by Wong et al. [26], complete biliary stone clearance with SOCguided LL was successful in $94 \%$ of patients (16/17) in a median of 1 endoscopic procedure (range, 1 to 3 ). The median duration of SOC-guided LL was 90 minutes (range, 46 to 164 ). This suggests that SOC with LL is effective for the management of difficult BDSs.

\section{EHL vs. LL}

We use both EHL and LL in our patients with biliary stones, according to endoscopist preference and equipment availability. A recent multicenter study compared EHL and LL by analyzing 407 patients [27]. This retrospective study compared the outcomes of 306 patients submitted to EHL and 101 patients treated with LL. The final clearance rate was similar for the two techniques (96.7\% for EHL and $99 \%$ for LL). The ducts were cleared in a single session in $77.4 \%$ of patients. However, a trend favoring LL with respect to efficacy was observed in a single initial session (74.5\% for EHL and $86.1 \%$ for LL, $p=0.20)$. The mean procedure time was significantly longer in the EHL group (73.9 minutes) than in the LL group (49.9 minutes, $p<0.001$ ).

A recent systematic review showed that LL had a higher complete ductal clearance rate (95.1\%) than EHL (88.4\%, $p<0.001$ ) [36]. Also, the AE rate was significantly higher with EHL (13.8\%) than with LL (9.6\%, $p=0.04)$. Thus, LL provides better clinical outcomes in difficult BDSs; however, it may depend on local expertise and the availability of each technique.

However, those studies did not explore the number of probes used and did not provide recommendations for choosing between EHL and LL. Further studies and guidelines that compare EHL and LL, including cost-effectiveness analyses, are needed.

EHL probes have a short life span, which is proportional to the power used during lithotripsy. In contrast, LL probes do not have this limitation but are more expensive. In addition, the generator/system is much more expensive. Probably, laser probes should be selected only in cases of very large, multiple, or hard stones, to overcome the life-span limitation of the EHL probe. 


\section{SOC-guided lithotripsy vs. direct POC-guided lith- otripsy}

Few studies have directly compared SOC-guided lithotripsy with direct POC-guided lithotripsy. In a systematic review of 49 studies, Korrapati et al. [28] analyzed the efficacy of POC for difficult BDSs. The overall estimated stone clearance rate was $88 \%$ ( $95 \% \mathrm{CI}, 85 \%$ to $91 \%)$. Additionally, they identified a significant association between the type of POC used and the technical success rate, with SOC demonstrating a higher technical success rate than the other methods $(p<0.01)$. Direct POC involving the use of an ultra-slim endoscope by a single endoscopist is technically difficult. Moreover, because an ultra-slim endoscope is thicker than SpyGlass, cannulating a nondilated bile duct is more difficult using the former. The need for direct POC had decreased recently because of the widespread use of SpyGlass. However, because SpyGlass is extremely expensive, direct POC can be a good treatment option for difficult BDSs in centers where the use of SpyGlass is not possible.

\section{SOC-guided lithotripsy vs. conventional ERCP (EPLBD and/or ML)}

SOC-guided lithotripsy has been reported to have a better stone clearance rate than conventional ERCP (EPLBD and/or ML). However, there are advantages and disadvantages to consider when deciding which procedure to perform.

Buxbaum et al. [37] randomized patients with difficult BDSs at a 2:1 ratio to SOC-guided LL and conventional therapy alone. Complete clearance was achieved in $93 \%$ of patients treated with SOC-guided LL and in $67 \%$ of those treated with conventional therapy alone ( $p=0.009)$. However, SOC-guided LL was associated with a longer procedure time $(120.7 \pm 40.2$ minutes in the conventional group and $81.2 \pm 49.3$ minutes in the SOC-guided LL group, $p=0.0008)$. The authors concluded that SOC-guided LL has a significantly higher stone clearance rate and a lower need for surgery than conventional therapy alone, although it is associated with a longer procedure time.

The randomized controlled trial by Angsuwatcharakon et al. [33] compared SOC-guided LL and ML after a failed EPLBD. The complete stone removal rates in a single session were $100 \%$ and $63 \%$ with comparable $\mathrm{AE}$ rates $(6 \%$ and $13 \%)$ in the SOC-guided LL and ML groups, respectively. In this study, the procedure time was not significantly different between the two groups (66 minutes vs. 83 minutes, $p=0.23$ ), although the radiation exposure was significantly lower $(20,989 \mathrm{mGy}$ $\mathrm{cm}^{2}$ vs. $40,745 \mathrm{mGy} \mathrm{cm}^{2}, p=0.04$ ) in the SOC-guided LL group. The rate of AEs was not different between the two groups $(13 \%$ in the ML group vs. $6 \%$ in the LL group, $p$ $=0.76)$.

Therefore, although ML is the standard procedure for difficult BDSs, SOC-guided lithotripsy is the more effective and safer treatment option and should be considered when available.

\section{Role of SOC in the management of IHD stones}

As mentioned earlier, SOC-guided lithotripsy is mainly used in the treatment of extrahepatic BDSs. However, few studies have investigated the efficacy of SOC in the management of IHD stones. The application of SOC in the removal of IHD stones is technically challenging. Usually, percutaneous transhepatic cholangioscopy (PTC) is the standard endoscopic method for the management of IHD stones in patients with a high operation risk, those who refuse surgery, and those with a previous hepatobiliary surgery or stones distributed in multiple parts of the liver. IHD stones are problematic to remove with ERCP because the IHD is difficult to access using the devices or accessories. This limitation can be overcome to some extent with SOC. Because the diameter of the cholangioscope is about $3.5 \mathrm{~mm}$, access to the IHD is easier than with other types of cholangioscopy systems. With SOC, after finding the IHD site where the stone is located, the guidewire is placed, and the stones can be removed using a balloon and a basket over the guidewire. Although SOC is technically more difficult than PTC, it has the advantage of providing an excellent quality of life for patients because it requires simple patient preparation, takes a short time to complete, and does not require a transcutaneous route. Further studies and case reports on SOC-guided management of IHD stones are needed to develop appropriate guidelines.

\section{Adverse events}

Post-ERCP AEs include pancreatitis, bleeding, cholangitis, perforation, and cardiopulmonary complications. Generally, AEs after ERCP have been reported to occur in $7 \%$ of patients [38]. With respect to SOC, previous 
studies have reported rates of AEs ranging from $0 \%$ to $16.4 \%[26,27,32,34,39-44]$. The profiles of SOC-related AEs are not different from those after conventional ERCP [44]. However, SOC-guided lithotripsy is more likely to have different or more frequent AEs than diagnostic SOC procedures because it has a longer procedure time and is intended for therapeutic use.

In a recent meta-analysis of 31 studies, the estimated overall AE rate was 7\% (95\% CI, 6\% to 9\%) [28]. The estimated rates of pancreatitis and cholangitis were $2 \%$ (95\% CI, $2 \%$ to $3 \%$ ) and $4 \%$ (95\% CI, 3\% to 5\%), respectively. The estimated rate of severe AEs was 1\% (95\% CI, 1\% to $2 \%)$. In several studies, including this one, cholangitis was the most frequently reported AE $[24,25,34,43]$. Sethi et al. [43] suggested that ERCP with cholangioscopy may be associated with higher total rates of AEs, especially cholangitis, despite antibiotic prophylaxis. The authors proposed that this risk could be explained by the increased pressure associated with water irrigation during the procedure. Pancreatitis is a rare AE, probably due to the high proportion of a preexistent EST state [34].

Overall, the available data suggest that SOC-guided lithotripsy is an effective and safe procedure for the management of difficult BDSs.

\section{Limitations}

The most important consideration in SOC-guided lithotripsy is the cost factor. The high cost, limited availability, and high endoscopist skill requirements of SOC hamper its widespread use.

EST with EPLBD and/or ML has the advantage of being relatively inexpensive and widely available compared with SOC-guided lithotripsy. In particular, in SOC-guided lithotripsy, it is important to consider that approximately $20 \%$ of patients require more than a single EHL/LL session. However, in the cost-effectiveness analysis by Deprez et al. [45], the use of a cholangioscope for difficult BDSs decreased the number of procedures and the cost by $28 \%$ and $11 \%$, respectively.

It is important that proven and effective techniques (e.g., ML/EPLBD) for the treatment of difficult BDSs are adequately considered before proceeding with SOC-guided lithotripsy. Future randomized studies comparing conventional ERCP and SOC-guided lithotripsy are needed to define the treatment

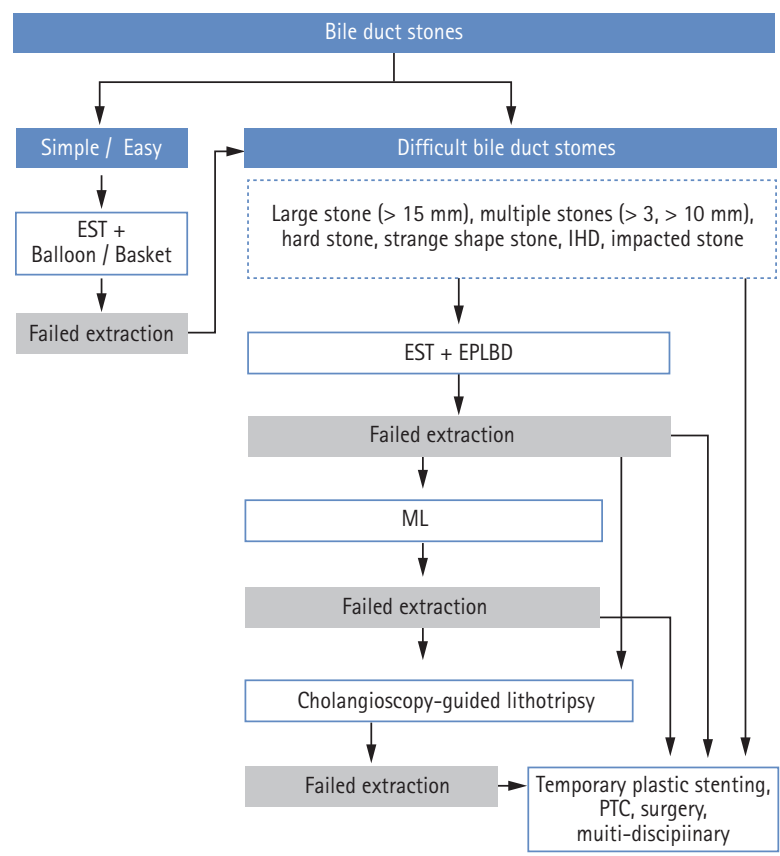

Figure 4. Treatment algorithm for the management of difficult bile-duct stones. EST, endoscopic sphincterotomy; IHD, intrahepatic duct; EPLBD, endoscopic papillary large balloon dilatation; ML, mechanical lithotripsy; PTC, percutaneous transhepatic cholangioscopy.

The technical limitations of SOC-guided lithotripsy should also be considered. As mentioned earlier, treatment using SOC may be difficult if it is not possible to fill the bile duct with saline, if it is difficult to insert the EHL or LL probe through the channel of the cholangioscope (SpyScope), or if the location of the stones is difficult to access with a cholangioscope (such as the IHD). Therefore, the optimal management of difficult BDSs requires a multidisciplinary approach, including an endoscopist, a surgeon, and an interventional radiologist, before and/or after surgery. Furthermore, it is important to remember that what is challenging for one ERCP endoscopist may not be as challenging for another.

\section{CONCLUSIONS}

In clinical practice, clearance of BDSs is often not achievable with conventional ERCP. If the removal of these difficult BDSs is impossible with $\mathrm{ML}$ or EPLBD, cholangioscopy-guided lithotripsy represents 
an emerging alternative technique for stone fragmentation and extraction. Subsequent to the development and widespread use of SOC, SOC-guided lithotripsy has been established as an excellent treatment option for the management of difficult BDSs. In cases for which SOC-guided lithotripsy is needed, endoscopists should be aware of the indications, techniques, treatment results, and management of possible complications of the procedure.

\section{Conflict of interest}

No potential conflict of interest relevant to this article was reported.

\section{REFERENCES}

1. Collins C, Maguire D, Ireland A, Fitzgerald E, O'Sullivan GC. A prospective study of common bile duct calculi in patients undergoing laparoscopic cholecystectomy: natural history of choledocholithiasis revisited. Ann Surg 2004;239:28-33.

2. Freitas ML, Bell RL, Duffy AJ. Choledocholithiasis: evolving standards for diagnosis and management. World J Gastroenterol 2006;12:3162-3167.

3. Yasuda I, Itoi T. Recent advances in endoscopic management of difficult bile duct stones. Dig Endosc 2013;25:376385 .

4. Manes G, Paspatis G, Aabakken L, et al. Endoscopic management of common bile duct stones: European Society of Gastrointestinal Endoscopy (ESGE) guideline. Endoscopy 2019;51:472-491.

5. Ersoz G, Tekesin O, Ozutemiz AO, Gunsar F. Biliary sphincterotomy plus dilation with a large balloon for bile duct stones that are difficult to extract. Gastrointest Endosc 2003;57:156-159.

6. Li G, Pang Q, Zhang X, et al. Dilation-assisted stone extraction: an alternative method for removal of common bile duct stones. Dig Dis Sci 2014;59:857-864.

7. Jun Bo Q, Li Hua X, Tian Min C, Liu Gen G, Yan Mei Y, Hua Sheng L. Small endoscopic sphincterotomy plus large-balloon dilation for removal of large common bile duct stones during ERCP. Pak J Med Sci 2013;29:907-912.

8. Kim JH, Yang MJ, Hwang JC, Yoo BM. Endoscopic papillary large balloon dilation for the removal of bile duct stones. World J Gastroenterol 2013;19:8580-8594.
9. Riemann JF, Seuberth K, Demling L. Mechanical lithotripsy of common bile duct stones. Gastrointest Endosc 1985;31:207-210.

10. Garg PK, Tandon RK, Ahuja V, Makharia GK, Batra Y. Predictors of unsuccessful mechanical lithotripsy and endoscopic clearance of large bile duct stones. Gastrointest Endosc 2004;59:601-605.

11. Cipolletta L, Costamagna G, Bianco MA, et al. Endoscopic mechanical lithotripsy of difficult common bile duct stones. Br J Surg 1997;84:1407-1409.

12. Lee SH, Park JK, Yoon WJ, et al. How to predict the outcome of endoscopic mechanical lithotripsy in patients with difficult bile duct stones? Scand J Gastroenterol 2007;42:1006-1010.

13. Chang WH, Chu CH, Wang TE, Chen MJ, Lin CC. Outcome of simple use of mechanical lithotripsy of difficult common bile duct stones. World J Gastroenterol 2005;11:593-596.

14. Chung SC, Leung JW, Leong HT, Li AK. Mechanical lithotripsy of large common bile duct stones using a basket. Br J Surg 1991;8:1448-1450.

15. Thomas M, Howell DA, Carr-Locke D, et al. Mechanical lithotripsy of pancreatic and biliary stones: complications and available treatment options collected from expert centers. Am J Gastroenterol 2007;102:1896-1902.

16. Ryozawa S, Yasuda I. Current strategies for the endoscopic management of difficult-to-treat bile duct stones in Japan. Dig Endosc 2018;30 Suppl 1:54-58.

17. Doshi B, Yasuda I, Ryozawa S, Lee GH. Current endoscopic strategies for managing large bile duct stones. Dig Endosc 2018;30 Suppl 1:59-66.

18. Franzini T, Moura RN, Bonifacio P, et al. Complex biliary stones management: cholangioscopy versus papillary large balloon dilation. A randomized controlled trial. Endosc Int Open 2018;6:E131-E138.

19. Bhandari S, Bathini R, Sharma A, Maydeo A. Usefulness of single-operator cholangioscopy-guided laser lithotripsy in patients with Mirizzi syndrome and cystic duct stones: experience at a tertiary care center. Gastrointest Endosc 2016;84:56-61.

20. Ishida Y, Itoi T, Okabe Y. Types of peroral cholangioscopy: how to choose the most suitable type of cholangioscopy. Curr Treat Options Gastroenterol 2016;14:210-219.

21. Ishida Y, Itoi T, Okabe Y. Current status and future perspective in cholangiopancreatoscopy. Curr Treat Options Gastroenterol 2019;17:327-341. 
22. Lux G, Ell C, Hochberger J, Muller D, Demling L. The first successful endoscopic retrograde laser lithotripsy of common bile duct stones in man using a pulsed neodymium-YAG laser. Endoscopy 1986;18:144-145.

23. Trikudanathan G, Navaneethan U, Parsi MA. Endoscopic management of difficult common bile duct stones. World J Gastroenterol 2013;19:165-173.

24. Patel SN, Rosenkranz L, Hooks B, et al. Holmium-yttrium aluminum garnet laser lithotripsy in the treatment of biliary calculi using single-operator cholangioscopy: a multicenter experience (with video). Gastrointest Endosc 2014;79:344-348.

25. Maydeo A, Kwek BE, Bhandari S, Bapat M, Dhir V. Single-operator cholangioscopy-guided laser lithotripsy in patients with difficult biliary and pancreatic ductal stones (with videos). Gastrointest Endosc 2011;74:1308-1314.

26. Wong JC, Tang RS, Teoh AY, Sung JJ, Lau JY. Efficacy and safety of novel digital single-operator peroral cholangioscopy-guided laser lithotripsy for complicated biliary stones. Endosc Int Open 2017;5:E54-E58.

27. Brewer Gutierrez OI, Bekkali NLH, Raijman I, et al. Efficacy and safety of digital single-operator cholangioscopy for difficult biliary stones. Clin Gastroenterol Hepatol 2018;16:918-926.

28. Korrapati P, Ciolino J, Wani S, et al. The efficacy of peroral cholangioscopy for difficult bile duct stones and indeterminate strictures: a systematic review and meta-analysis. Endosc Int Open 2016;4:E263-E275.

29. Bokemeyer A, Gerges C, Lang D, et al. Digital single-operator video cholangioscopy in treating refractory biliary stones: a multicenter observational study. Surg Endosc 2020;34:1914-1922.

30. Kurihara T, Yasuda I, Isayama H, et al. Diagnostic and therapeutic single-operator cholangiopancreatoscopy in biliopancreatic diseases: prospective multicenter study in Japan. World J Gastroenterol 2016;22:1891-1901.

31. Navaneethan U, Hasan MK, Kommaraju K, et al. Digital, single-operator cholangiopancreatoscopy in the diagnosis and management of pancreatobiliary disorders: a multicenter clinical experience (with video). Gastrointest Endosc 2016;84:649-655.

32. Turowski F, Hugle U, Dormann A, et al. Diagnostic and therapeutic single-operator cholangiopancreatoscopy with SpyGlassDS ${ }^{\text {TM}}$ : results of a multicenter retrospective cohort study. Surg Endosc 2018;32:3981-3988.

33. Angsuwatcharakon P, Kulpatcharapong S, Ridtitid W, et al. Digital cholangioscopy-guided laser versus mechanical lithotripsy for large bile duct stone removal after failed papillary large-balloon dilation: a randomized study. Endoscopy 2019;51:1066-1073.

34. Chen YK, Parsi MA, Binmoeller KF, et al. Single-operator cholangioscopy in patients requiring evaluation of bile duct disease or therapy of biliary stones (with videos). Gastrointest Endosc 2011;74:805-814.

35. Jin Z, Wei Y, Tang X, et al. Single-operator peroral cholangioscope in treating difficult biliary stones: a systematic review and meta-analysis. Dig Endosc 2019;31:256-269.

36. Veld JV, van Huijgevoort NCM, Boermeester MA, et al. A systematic review of advanced endoscopy-assisted lithotripsy for retained biliary tract stones: laser, electrohydraulic or extracorporeal shock wave. Endoscopy 2018;50:896-909.

37. Buxbaum J, Sahakian A, Ko C, et al. Randomized trial of cholangioscopy-guided laser lithotripsy versus conventional therapy for large bile duct stones (with videos). Gastrointest Endosc 2018;87:1050-1060.

38. Andriulli A, Loperfido S, Napolitano G, et al. Incidence rates of post-ERCP complications: a systematic survey of prospective studies. Am J Gastroenterol 2007;102:1781-1788.

39. Lenze F, Bokemeyer A, Gross D, Nowacki T, Bettenworth D, Ullerich H. Safety, diagnostic accuracy and therapeutic efficacy of digital single-operator cholangioscopy. United European Gastroenterol J 2018;6:902-909.

40. Imanishi M, Ogura T, Kurisu Y, et al. A feasibility study of digital single-operator cholangioscopy for diagnostic and therapeutic procedure (with videos). Medicine (Baltimore) 2017;96:e6619.

41. Kamiyama R, Ogura T, Okuda A, et al. Electrohydraulic lithotripsy for difficult bile duct stones under endoscopic retrograde cholangiopancreatography and peroral transluminal cholangioscopy guidance. Gut Liver 2018;12:457-462.

42. Ogura T, Imanishi M, Kurisu Y, et al. Prospective evaluation of digital single-operator cholangioscope for diagnostic and therapeutic procedures (with videos). Dig Endosc 2017;29:782-789.

43. Sethi A, Chen YK, Austin GL, et al. ERCP with cholangiopancreatoscopy may be associated with higher rates of complications than ERCP alone: a single-center experience. Gastrointest Endosc 2011;73:251-256.

44. Lubbe J, Arnelo U, Lundell L, et al. ERCP-guided cholangioscopy using a single-use system: nationwide regis- 
ter-based study of its use in clinical practice. Endoscopy 2015;47:802-807.

45. Deprez PH, Garces Duran R, Moreels T, et al. The economic impact of using single-operator cholangioscopy for the treatment of difficult bile duct stones and diagnosis of indeterminate bile duct strictures. Endoscopy 2018;50:109-118. 